\title{
Correlation between Procalcitonin, Erythrocyte Sedimentation Rate and Red-Cell Distribution Width with Outcomes in ALL
}

\author{
Nathalya Dwi Kartika Sari ${ }^{1}$, I.G.A.A Putri Sri Rejeki ${ }^{1}$, I. Dewa Ugrasena ${ }^{2}$ \\ ${ }^{1}$ Department of Clinical Pathology, Faculty of Medicine, Airlangga University/Dr. Soetomo Hospital, Surabaya, Indonesia. E-mail: \\ nathalyadwiks@gmail.com \\ ${ }^{2}$ Department of Pediatrics, Faculty of Medicine, Airlangga University/Dr. Soetomo Hospital, Surabaya, Indonesia
}

\begin{abstract}
Acute Lymphoblastic Leukemia (ALL) increases annually and the incidence is mostly found in children. Its high failure rate is due to infection in the induction phase of chemotherapy. One of the strategies is laboratory testing to determine prognostic factors or predictors that can help clinicians determine therapy and outcomes in ALL. Research related to Procalcitonin (PCT), Erythrocyte Sedimentation Rate (ESR), and Red-cell Distribution Width (RDW) test in ALL children with poor outcomes has never been performed at Dr. Soetomo Hospital, Surabaya. This study aimed to determine the correlation of some infection parameters (PCT, ESR, and RDW) with outcomes in ALL. This was a cross-sectional study in the Pediatric Ward of the Dr. Soetomo Hospital in the period of June-August 2019. A total of 34 ALL patients after the induction phase of chemotherapy according to ALL-2018 protocol were included in this research. Procalcitonin, ESR, and RDW were determined using an ELFA method, photometrical capillary stopped-flow kinetic method, and flow cytometry method. The age of the study subjects ranged from 3 months to 16 years old, 32 patients (94.1\%) were categorized as ALL-L1, 23 patients (67.6\%) used protocol of high-risk group stratification. The study subjects were divided into 10 patients with poor outcomes and 24 patients with a good outcome. Procalcitonin was (2.66 \pm 13.15$)$, ESR was (22.65 \pm 19.18$)$, and RDW was (14.97 \pm 2.727$)$. There was a significant correlation between PCT and outcomes.
\end{abstract}

Keywords: Acute lymphoblastic leukemia, children, procalcitonin, erythrocyte sedimentation rate, red-cell distribution width, outcomes

\section{INTRODUCTION}

Acute Lymphoblastic Leukemia (ALL) is one type of cancer that continues to increase each year and is frequently found in children. ${ }^{1,2}$ A total of 620 new ALL cases were obtained in Dr. Soetomo Hospital, Surabaya from 2014 to 2018 , with $39 \%$ of those cases showed poor outcomes, which required therapy and $30 \%$ because of severe infection. ${ }^{3}$ This showed that the high rate of treatment failure is due to infection in the induction phase of ALL treatment.

Pediatric ALL chemotherapy used in the Dr. Soetomo Hospital, Surabaya was according to the National Protocol ALL-2018, which consists of 4 phases such as induction, consolidation, intensification, and maintenance phases. Remission in the induction phase plays an important role in the prognosis of pediatric ALL patients. Chemotherapy provides greater hope of recovery, although it remains the biggest contributor to cancer deaths in children. Strategies to reduce the incidence and mortality are needed for this disease. One such strategy is a laboratory test to determine prognostic factors or predictors that can help clinicians determine the therapies and outcomes needed by pediatric ALL patients.

Research using PCT as a marker of infection in pediatric ALL began to be widely published. Procalcitonin was first published in 1983. Procalcitonin is a protein that can act as a hormone and cytokines produced by certain cells and organs, as a stimulus-response to pro-inflammatory, bacterial infections, PCT itself can be used as a diagnostic and prognostic infectious disease. Procalcitonin provides relatively faster results than blood culture, a more specific marker in sepsis patients with immunocompromised and immunodeficient conditions, and can monitor disease severity. Procalcitonin is significantly increased in bacterial infections, can be an initial diagnosis of disease severity, and an increase in PCT can also occur in agranulocyte patients accompanied by bacterial infections after receiving ALL chemotherapy. ${ }^{4}$

Erythrocyte sedimentation rate test is easy to do, simple, and its increased value can indicate 
hematological abnormalities with infection, inflammation, the presence or absence of pathological conditions in malignancies, and monitor the outcome of treatment given by doctors. ${ }^{5}$ Red-cell Distribution Width (RDW) is a part of a complete blood count parameter used as an important prognostic marker in sepsis patients. ${ }^{6}$ Red-cell distribution width is a heterogeneity index of the size of erythrocytes, which is often associated with the presence of inflammatory processes, impaired kidney function, and malnutrition. Hematologic malignancies have been known to have an association with inflammation and malnutrition using the RDW parameter as a predictor of cancer. ${ }^{7-9}$

The parameters of PCT, ESR, and RDW in laboratories are found in almost all hospitals, especially referral hospitals. The correlation between PCT, ESR, and RDW with pediatric ALL patients is expected to be able to predict therapeutic outcomes, thus increasing cure rates. Research related to PCT, $E S R$, and RDW test in ALL malignancies in children with outcomes has never been performed at the Dr. Soetomo Hospital, Surabaya and other parts of Indonesia, encouraging the authors to perform this research.

This study aimed to determine the correlation between PCT, ESR, and RDW with the outcome of pediatric ALL during the induction phase of chemotherapy treatment using the National Protocol ALL 2018.

\section{METHODS}

This was cross-sectional observational analytical research. Blood sampling was taken from the Pediatric ward and Hemato-Oncology Pediatric Laboratory. This study was carried out from December to September 2019. The samples consisted of ALL pediatric patients undergoing chemotherapy induction phase according to National ALL Protocol 2018 at the Dr. Soetomo Hospital Surabaya.

The study samples were ALL pediatric patients on a consecutive basis, sampling was taken from April until September 2019 and 35 study samples were found. Thirty-four samples met the inclusion criteria, while one sample was excluded. The patients had filled out an informed consent. Inclusion criteria in this research were pediatric ALL patients, aged 0-16 years old whose family agreed and signed the informed consent, received induction phase chemotherapy using the ALL-Protocol 2018, while exclusion criteria were patients with ALL-L3, ALL with complex congenital disorders, and multi-organ disorders before chemotherapy such as MODS, severe sepsis, patients who did not complete the induction phase treatment and withdrew from research participation.

A total of $\pm 3 \mathrm{~mL}$ blood samples were taken from pediatric patients undergoing induction phase chemotherapy who met the inclusion criteria. Blood was centrifuged and $\pm 1 \mathrm{~mL}$ serum was collected and $\pm 200 \mu$ of it will be tested for procalcitonin by ELFA method with Vidas instrument. The $\pm 2 \mathrm{~mL}$ remaining sample of whole blood will be tested for RDW with the Cell-Dyn Ruby instrument and ESR with ALIFAX instrument. The test results were analyzed after completing the induction phase of chemotherapy and data were then processed and statistically analyzed.

Data were analyzed with SPSS 17.0 using frequency distribution tables. Ordinal outcomes (non-remission, relapse, and death) were analyzed by the Spearman rank test. A p-value $<0.05$ was considered as a significant result.

This research has received approval from the Health Research Ethics Committee of Dr. Soetomo Hospital, Surabaya with a number of 1231/5/19. Research subjects participating in this study already signed informed consent.

\section{RESULTS AND DISCUSSIONS}

Sampling was carried out from December to September 2019 comprising a number of $35 \mathrm{ALL}$ pediatric patients who received induction phase chemotherapy, $34 \mathrm{ALL}$ patients according to inclusion criteria, while one patient was excluded. A description of the characteristics of the research subjects was shown as follows (Table 1 ).

Table 1. Characteristics of research subjects

\begin{tabular}{lll}
\hline \multicolumn{1}{c}{ Characteristics } & $\mathbf{n}$ & \% \\
\hline Gender & & \\
$\quad$ Male & 24 & 70.6 \\
$\quad$ Female & 10 & 29.4 \\
Type ALL & & \\
$\quad$ L1 & 32 & 94,1 \\
L2 & 2 & 5.9 \\
Risk stratification & & \\
$\quad$ SR & 11 & 32.4 \\
$\quad$ HR & 23 & 67.6 \\
Age(year) & & \\
$\quad$ Mean $\pm S D$ & $6.093 \pm 3.629$ \\
$\quad$ Median (min-max) & $5.5(0.25-16)$ \\
\hline
\end{tabular}


Based on Table 1 it could be informed that the most ALL patients in this study sample were boys as many as 24 children (70.6\%) and girls as many as 10 children (29.4\%). ALL-L1 type was dominant with a total of 32 children (94.1\%). The stratification of high-risk groups of 23 children (67.6\%) was dominant. The average age of 34 sample patients was known to be 6 years with a standard deviation of approximately 4 years, which indicated that the age diversity of sample patients was quite large.

Other descriptions for the research variables referred to the results of measurements of 34 sample patients including PCT, ESR, and RDW can be explained as follows (Table 2).

Table 2. Description of research variables

\begin{tabular}{lcc}
\hline & N & Mean \pm SD \\
\hline PCT $(\mathrm{ng} / \mathrm{mL})$ & 34 & $2.66 \pm 13.146$ \\
ESR (mm/hour) & 34 & $22.65 \pm 19.182$ \\
RDW (\%) & 34 & $14.97 \pm 2.727$ \\
\hline
\end{tabular}

The description of research variables after receiving induction phase chemotherapy according to the National ALL Protocol 2018 showed a tendency that there were 24 (70.6\%) remissive patients. The remaining poor outcomes consisted of 3 (8.8\%) non-remissive patients and 7 (20.6\%) patients died. More detailed outcomes from 34 patients can be seen in Figure 1 .

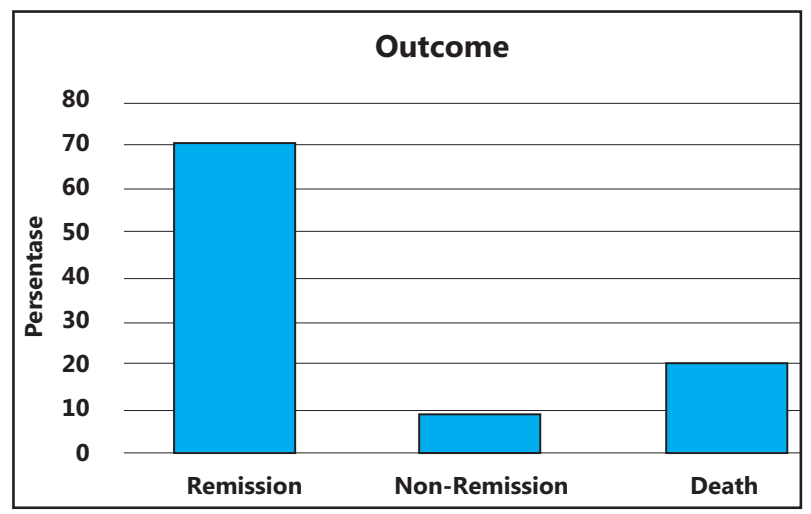

Figure 1. Pediatric ALL outcome with induction phase chemotherapy

Referring to Table 3, it was known that the levels of PCT for patients with death outcomes had the highest average compared to the other categories, as well as the results of measurements of ESR and RDW. Figures 2, 3, and 4 showed that measurements on PCT, ESR, and RDW tended to be high in poor outcomes (death).
Table 3. Description of research variables based on outcomes

\begin{tabular}{llcc}
\hline & \multicolumn{1}{c}{ Outcomes } & N & Mean \pm SD \\
\hline PCT $(\mathbf{n g} / \mathbf{m L})$ & Non-remission & 3 & $0.88 \pm 0.72$ \\
& Remission & 24 & $0.25 \pm 0.25$ \\
& Death & 7 & $11.69 \pm 28.81$ \\
ESR (mm/hour) & Non-remission & 3 & $23.33 \pm 2.08$ \\
& Remission & 24 & $19.88 \pm 19.26$ \\
& Death & 7 & $31.86 \pm 21.69$ \\
RDW (\%) & Non-remission & 3 & $13.13 \pm 0.93$ \\
& Remission & 24 & $14.77 \pm 2.39$ \\
& Death & 7 & $16.44 \pm 3.80$ \\
\hline
\end{tabular}

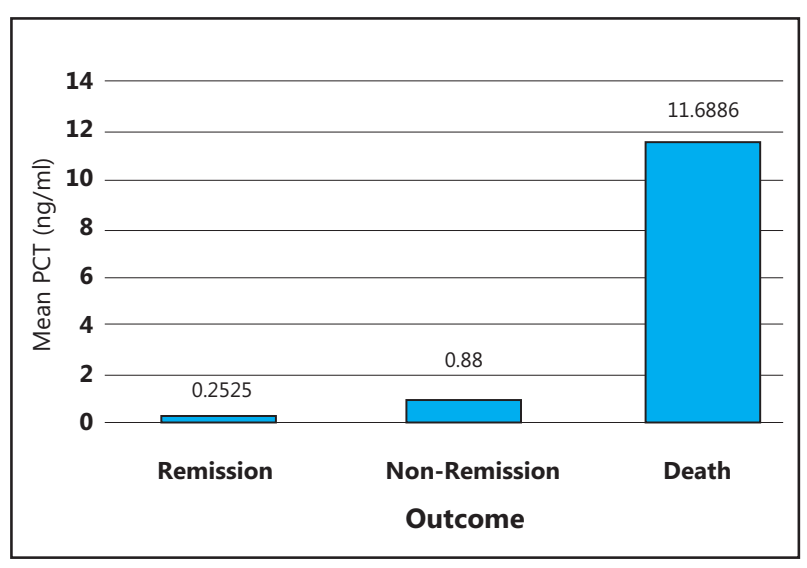

Figure 2. Mean PCT in poor outcome (death)

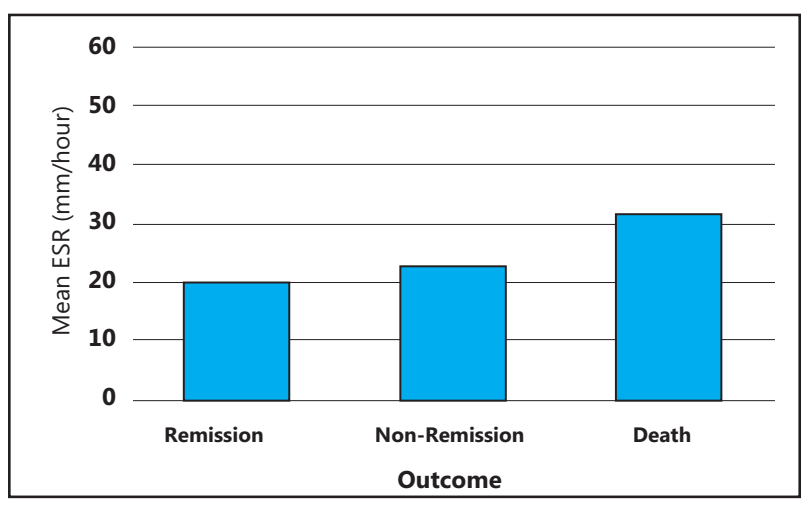

Figure 3. Mean ESR in poor outcome (death)

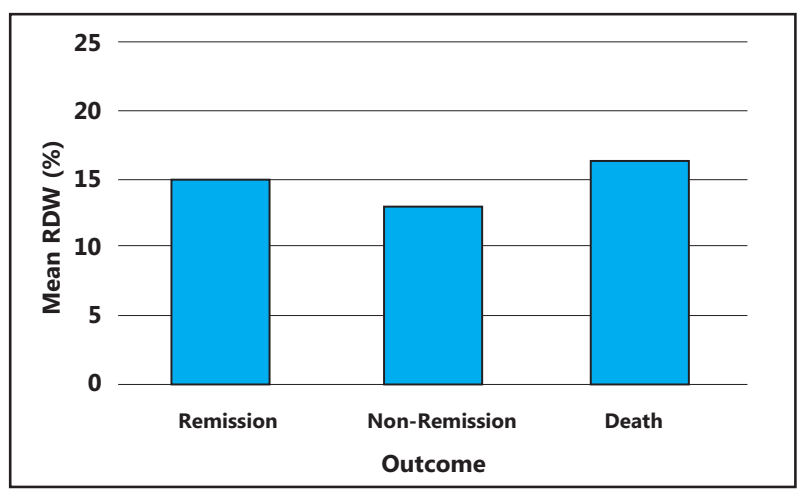

Figure 4. Mean RDW in poor outcome (death) 
Table 4. The correlation of PCT, ESR, and RDW to all outcomes using Spearman rank test

\begin{tabular}{llll}
\hline $\begin{array}{l}\text { Correlation } \\
\text { with Outcomes }\end{array}$ & $\mathbf{n}$ & Coefficient of Correlation Spearman $\left(\mathbf{r}_{\mathbf{s}}\right)$ & p-value \\
\hline PCT & 34 & 0.541 & 0.001 \\
LED & 34 & 0.245 & 0.162 \\
RDW & 34 & 0.090 & 0.613 \\
\hline
\end{tabular}

The correlation between procalcitonin, ESR, and RDW with the outcomes after receiving induction phase chemotherapy according to the ALL Protocol 2018 can be seen in Table 4.

A total of $24(70.6 \%)$ male subjects were obtained from 34 subjects in this study. A study conducted by Li et al. showed that the proportion ratio two sexes was nearly balanced. ${ }^{10}$ These results differed from studies by the Hasan Sadikin Hospital Bandung (RSHS) using more patients with 70\% LLA-L2. ${ }^{11}$

This study had more (76.4\%) high-risk groups compared to standard risk, according to the research conducted at RSHS, which obtained high-risk stratification of $65 \%$ compared to standard risk. ${ }^{11}$ Risk stratification depended on the number of leukocytes, the patient's age and treatment results, whereas patients aged 18 months or over 10 years had a worse prognosis than patients aged between it. ${ }^{12}$ Gender, the type of ALL, and risk group stratification in this study were not further analyzed.

The average standard deviation of PCT in this study was a significant deviation from the median obtained, according to a study by Widijanti, which compared laboratory instruments and obtained a large range $(0.05-200 \mathrm{ng} / \mathrm{mL})$ in Vidas compared to other procalcitonin test instruments. ${ }^{13}$

The RDW standard deviation in this study was in accordance with the mean value in a study by Rafsanjani in pediatric ALL patients, with a mean of $16 \%$ and an average of $11.2 \%-23.25 \%{ }^{14}$

The induction phase was a part of intensive chemotherapy that must be carried out correctly and on time according to the protocol to reach the final condition of complete remission. ${ }^{15}$ This study obtained a remission outcome of $70.6 \%$ (Figure 1 ). This was consistent with previous studies conducted at the Dr. Soetomo Hospital showing that remission pediatric ALL patients (33 patients/48.5\%) were higher in number than non-remission or dead patients based on bone marrow aspiration, as well as a study in RSHS, which found 20 patients in remission (76.9\%) after having induction phase chemotherapy compared to non-remission. ${ }^{11}$ The choice of chemotherapy indirectly affected the outcome. Clinical trials with the selection of therapies according to the protocol were adjusted in each country. ${ }^{16}$

This study found that PCT measurements tended to increase more in poor outcomes (Figure 2). The release of PCT from parenchymal tissue and cells throughout the body would increase during bacterial infections leading to increased CALC-1 expression. The release of PCT is influenced by 2 ways, a direct way through toxins or lipopolysaccharides released by microbes, and an indirect way in cell response to inflammatory cytokines IL-1b, IL-6 and TNFa. ${ }^{10}$

The results of ESR measurements in this study tended to increase more in poor outcomes (Figure 2), increased ESR are associated with cell inflammation, stimulating carcinogenesis, DNA damage, and tumor cell proliferation, which ultimately stimulates angiogenesis and metastasis. Increased ESR with metastasis is more likely to cause predictions in the direction of poor outcomes. ${ }^{5}$

This study found that RDW results tended to increase in poor outcomes (died) (Figure 4), and this was following research by Mohanty et al., and Ai et al. Oxidative stress can interfere with the function of erythrocytes. Reactive Oxygen Species (ROS) are released by neutrophils, macrophages, and endothelial cells into the plasma. Some oxygenated $\mathrm{Hb}$ molecules are found in erythrocytes in the microcirculation, while oxygen is delivered by $\mathrm{Hb}$ to tissues that have an increased affinity for erythrocyte membranes and have an increased auto-oxidation that produces ROS, which is not completely neutralized by the erythrocyte antioxidant system. ${ }^{17}$ Inflammation triggered by ROS will interfere with erythropoiesis and changes in erythrocyte maturation, causing an increase in RDW. Digestive disorders that are often found in patients with malignancy result in impaired iron absorption, causing iron metabolic disorders and contribute to increased RDW. ${ }^{18}$

There was a significant correlation between PCT and outcomes in this study. Increased levels of procalcitonin are negatively correlated with the absolute neutrophil count but had a low correlation with a bacterial infection. ${ }^{19}$ Procalcitonin has limitations, unspecified increases in bacterial 
infections can occur in severe stress (trauma and surgery) or cardiac shock, as well as non-bacterial inflammatory conditions, newborn, combustion, transplantation, immunotherapy such as granulocyte transfusion, anti-lymphocyte globulin and anti-CD3 antibodies, therapy with cytokines associated with IL-2 and TNFa, and autoimmune diseases. $^{10}$

This study showed that there was no significant correlation between ESR and outcomes. The ESR examination must be used wisely to confirm a diagnosis based on clinical findings and monitoring of disease activity, where there is an increase ESR in malignant patients (53.1\%) compared to healthy patients, but the measurement of ESR is not an important screening procedure to find whether or not a disease occurred in malignancy. ${ }^{5}$

There was no significant correlation between RDW and outcomes in this study, and this result was in accordance with research conducted by Rafsanjani et al. in pediatric ALL patients, which concluded that there was no significant correlation between RDW with mortality or relapse. The correlation between RDW and cancer can only be described by inflammatory conditions and oxidative stress found in cancer. Research in Indonesia revealed that there was no significant difference between RDW and mortality in pediatric sepsis patients, it was influenced by several conditions such as infection, inflammation, and cardiopulmonary disease. ${ }^{20}$

$\mathrm{Ai}$ et al. revealed different results, whereas elevated RDW value had a worse prognosis compared to the low one. Research conducted by $\mathrm{Li}$ et al. had similar results, the relationship of RDW with cancer mortality was influenced by inflammation and anemia. ${ }^{21}$ Red-cell distribution width was a part of an inexpensive whole blood test to evaluate anemia, the prognosis, and the clinical condition of seriously ill patients with inflammation and heart disease. ${ }^{22}$

Test parameter, which was only taken once in the $6^{\text {th }}$ week of the induction phase remained a limitation in this study. Therefore, there was no explanation of the changes in the results of the parameters tested during induction phase chemotherapy, not to mention that the research was conducted in a relatively short period.

\section{CONCLUSIONS AND SUGGESTIONS}

There was a significant correlation between PCT and outcomes. Based on the result of this study, we recommend a similar study with serial PCT, ESR, and RDW collection techniques at 2, 4, and 6 weeks, to reveal changes in PCT, ESR, and RDW parameters in the induction phase of ALL patients. A longer period of further research is also necessary.

\section{ACKNOWLEDGMENT}

The researcher would like to thank the Department of Pediatrics for providing this research that could be finished. It was expected that this research can be useful and become the input for the parties in need.

\section{REFERENCES}

1. Satyanarayana L, Asthana S, Labani P. Childhood cancer incidence in India: A review of populationbased cancer registries. Indian Pediatrics, 2018; 59: 218-20.

2. Terwilliger T, Abdul-Hay M. Acute lymphoblastic leukemia: A comprehensive review and 2017 update. Blood Cancer Journal, 2017; 7(6): e577.

3. Data Divisi Hematologi Onkologi Departemen/SMF Ilmu Kesehatan Anak RSUD Dr. Soetomo tahun 2013 (Data tidak dipublikasikan).

4. Qu Z, Fang B, Ma G, Jiang J, Wang X, et al. Significance of procalcitonin in bacterial infections among acute leukemia patients with post-chemotherapy agranulocytosis. Srpski Arhiv Za Celokupno Lekarstvo, 2017; 145(7-8): 382-386.

5. Tas F, Erturk K. Elevated erythrocyte sedimentation rate is associated with metastatic disease and worse survival in patients with cutaneous malignant melanoma. Molecular and Clinical Oncology, 2017; 7: 1142-1146.

6. Jandial A, Kumar S, Bhala A, Navneet S, Varma N, Varma S. Elevated red cell distribution width as prognostic marker in severe sepsis: A prospective observational study. Indian J Crit care Med 2017; 21: 552-62.

7. Montagnana M, Danese E. Red cell distribution width and cancer. Annals of Translational Medicine, 2016; 4(20): 399-399.

8. Li B, You Z, Xiong XZ, Zhou Y, Wu SJ, et al. Elevated red cell distribution width predict poor prognosis in hilar cholangiocarcinoma. Oncotarget, 2017; 8(65): 109468-109477.

9. Kiriu T, Yamamoto M, Nagano T, Koyama K, Katsurada $\mathrm{M}$, et al. Prognostic value of red blood cell distribution width in non-small cell lung cancer treated with anti programm cell death-1 antibody. In-vivo, 2019; 33: 213-220.

10. Durmas B, Watek M, Wollny T, Niemirowicz K, Marzec $M$, et al. Utility of blood procalcitonin concentration in management of cancer patients with infections. Onco Targets Ther, 2016; 9: 469-475.

11. Suryawan N, Idjradinata $P$, Reniarti L. Hubungan subtipe sel limfosit dengan tingkat remisi pascakemoterapi fase induksi leukemia limfoblastik 
akut. Sari Pediatri, 2017; 18(6): 448.

12. Poernomo B, Ugrasena IG, Supriyadi. Buku ajar hematologi-onkologi anak edisi revisi. 2018; Bab 7 (276-285).

13. Widijanti A. Pengukuran prokalsitonin serum dengan test cepat FIA untuk deteksi sepsis. Materi PK Update Malang, FK Unbraw, 2019; 64-68.

14. Rafsanjani KA, Fallahi M, Kiumarsi A, Falahati V, Moghaddam $S$. The association between red cell distribution width and mortality in pediatric acute lymphoblastic leukemia. Journal of Neoplasm, 2018; 02(02): 1-3.

15. Protokol Nasional ALL 2018. Ikatan Dokter Anak Indonesia (data tidak dipublikasikan).

16. Rytting M, Jabbour E, O'Brien S, Kantarjian H. Review article acute lymphoblastic leukemia in adolescents and young adults. Wiley Online Library, 2017; 7(6): e577.

17. Mohanty J, Nagababu E, Rifkind J. Red blood cell oxidative strees impairs oxygen delivery and induces red blood cell aging. PubMed Central, 2014; 28; 5: 84.

18. Ai L, Mu S, Hu Y. Prognostic role of RDW in hematology malignancies: A systematic review and meta-analysis, primary research. BMC-Cancer Cell International, 2018; 18: 61.

19. Kapoor R , Simalti A, Roy S, Agarwal P. Hematological profile of febrile neutropenia in acute leukemia and utility of serum procalcitonin levels in neutropenic patients. Indian J. Crit Care Med, 2018; 22(5): 336-339.

20. Devina $T$, Lubis M, Mutiara E. Red cell distribution width and mortality in pediatric sepsis. Paediatric Indonesia, 2016; 56(6): 320-324.

21. Litao M, Kamat D. Red blood cell distribution width clinical use beyond hematology, back to basics. Pediatrics in Review, 2018; 39(4): 204-209.

22. Li J, Yang J, Gong F, Chen Q. Relationship of red blood cell distribution width with cancer mortality in hospital. Biomed Research International, 2018; 1: 1-8. 